\title{
Fundamental Reaction Limitations for Formic Acid
}

\section{Oxidation}

Alexander Bagger, ${ }^{\dagger, t a}$ Kim D. Jensen, ${ }^{\sharp, a}$ Maryam Rashedi, ${ }^{a, b}$ Rui Luo, ${ }^{a, c}$ Jia Du, ${ }^{d}$ Damin Zhang, ${ }^{d}$ Inês J. Pereira, ${ }^{a}$ María Escudero-Escribano, ${ }^{a}$ Matthias Arenz, ${ }^{a, d}$ and Jan Rossmeisl ${ }^{a}$

${ }^{a}$ University of Copenhagen, Department of Chemistry Universitetsparken 5, 2100 Kbh- $\varnothing$,

Denmark

${ }^{b}$ College of Science, University of Tehran, Enghelab square, Tehran, Iran

${ }^{c}$ School of Environmental and Biological Engineering, Nanjing University of Science \& Technology, Nanjing 210094, China

${ }^{d}$ University of Bern, Department of Chemistry, Biochemistry and Pharmaceutical Sciences, $\mathrm{CH}-$ 3012 Bern, Switzerland

KEYWORDS: FAOR, formic acid oxidation reaction, DFT, density functional theory, electrochemistry, electrocatalysis

ABSTRACT. Electrocatalytic conversion of formic acid oxidation to $\mathrm{CO}_{2}$ and the related $\mathrm{CO}_{2}$ reduction to formic acid represent a potential closed carbon-loop based on renewable energy. However, formic acid fuel cells are inhibited by the formation of poisoning species during the reaction. Recent studies have elucidated how the binding of carbon and hydrogen on catalyst 
surfaces promote $\mathrm{CO}_{2}$ reduction towards $\mathrm{CO}$ and formic acid. This has also given fundamental insights to the reverse reaction, i.e. the oxidation of formic acid. In this work, simulations on multiple materials have been combined with formic acid oxidation experiments on electrocatalysts to shed light on the reaction and the accompanying catalytic limitations. We found that: (i) The desired principal reaction for efficient formic acid oxidation should progress through adsorbed carboxyl, ${ }^{*} \mathrm{COOH}$, which should then be oxidized to $\mathrm{CO}_{2}$. (ii) ${ }^{*} \mathrm{H}$ adsorbed on the surface results in ${ }^{*} \mathrm{CO}$ formation and poisoning through a chemical disproportionation step. (iii) Catalysts are poisoned by formate and/or hydroxyl. Using these results, a framework for the reaction has been developed explaining the fundamental limitations and progressing our understanding.

\section{Introduction}

Tremendous efforts are currently going into out-phasing fossil fuels in favor of sustainable fuels. ${ }^{1}$ This is motivated by our need to close the carbon cycle ${ }^{2}$ as well as the decrease in renewable electricity prices, which simultaneously have paved the way for new fuel production routes. ${ }^{3}$ Electrocatalytic technologies propone direct electrification of chemical and fuel production. Examples include reduction of $\mathrm{CO}_{2}$ towards $\mathrm{HCOOH}, \mathrm{CH}_{3} \mathrm{OH}, \mathrm{C}_{2} \mathrm{H}_{5} \mathrm{OH}$ and $\mathrm{H}_{2} \mathrm{O}$ towards $\mathrm{H}_{2}{ }^{1}$ Efficient fuel consumption through fuel cells (FCs) also holds great potential. ${ }^{4}$ Liquid fuels such as formic acid and methanol have attracted a lot of attention due to their: Viable energy density per mass- and volume, attractive handling/storage properties and potential uses in other non-fuel applications, e.g. as a high value chemical building blocks for industry. ${ }^{3}$

Some liquid fuels such as methanol, are notoriously limited in the oxidation toward $\mathrm{CO}_{2}$ since the process goes through a $\mathrm{CO}$ intermediate. ${ }^{5} \mathrm{CO}$ oxidation then becomes the limiting factor determining the performance of direct methanol FCs (DMFCs). Formic acid as liquid fuel behaves 
differently; it has a $\mathrm{CO}_{2}$-like structure with two hydrogens attached. This molecular structure predicates that the oxidation process only requires the removal of two hydrogen atoms. Consequently, formic acid oxidation should ideally circumvent the problem of CO-poisoning.

To gauge formic acid's efficiency as a fuel we compare the single round trip efficiency of relevant closed-loop chemical compounds, i.e. hydrogen, formic acid, methanol and lithium batteries as seen in Table 1. Here we observe that the Li-battery storing and release of energy exhibits the highest efficiency followed by hydrogen. However, both Li-batteries and $\mathrm{H}_{2}$ suffer from low energy density. Storing energy as methanol and formic acid is very similar in terms of the cost in electrolyzer energy. The major difference between formic acid and methanol arises when using the chemical in a fuel cell, where methanol is limited by $\mathrm{CO}$ oxidation. ${ }^{6}$

Table 1. Estimated round-trip efficiencies $\left(\eta=\frac{U_{O R R}-U_{\text {Fuel }} \text { cell reaction }}{U_{O E R}+U_{\text {Electrolyzer reaction }}} \times 100 \%\right)$ calculated using the difference in energy potentials. Common for hydrogen, formic acid, and methanol we use $U_{O E R}=1.6 \mathrm{~V}_{\mathrm{RHE}}$ and $U_{O R R}=0.8 \mathrm{~V}_{\mathrm{RHE}}$. "Here only the cost of syngas production is considered, not the full formation of methanol. ** Typical charge/discharge efficiency.

\begin{tabular}{|c|c|c|c|}
\hline & $\begin{array}{l}\text { Energy stored } \\
\text { (electrolyzer) }\end{array}$ & $\begin{array}{l}\text { Energy released } \\
\text { (fuel cell) }\end{array}$ & $\begin{array}{l}\text { Round trip } \\
\text { efficiency, } \eta\end{array}$ \\
\hline Hydrogen & $U_{H E R}=-0.1 \mathrm{~V}_{\mathrm{RHE}}$ & $U_{H O R}=0.1 \mathrm{~V}_{\mathrm{RHE}}$ & $\approx 41 \%$ \\
\hline Formic acid & $U_{\mathrm{CO}_{2} \rightarrow \mathrm{HCOOH}}=-0.8 \mathrm{~V}_{\mathrm{RHE}}$ & $U_{F A O R}=0.2 V_{\mathrm{RHE}}$ & $\approx 25 \%$ \\
\hline Methanol* $^{*}$ & $U_{\mathrm{CO}_{2} \rightarrow \mathrm{CO}+\mathrm{H}_{2}}=-0.6 \mathrm{~V}_{\mathrm{RHE}}$ & $U_{\mathrm{CO} \rightarrow \mathrm{CO}_{2}}=0.65 \mathrm{~V}_{\mathrm{RHE}}$ & $\approx 7 \%$ \\
\hline Li-battery ${ }^{* *}$ & & & $\approx 90 \%$ \\
\hline
\end{tabular}


Depending on the $U_{F A O R}$, formic acid fuel cells can be considered an attractive alternative to methanol fuel cells. Methanol provides 6 protons per reacted molecule and formic acid only two and therefore methanol has a $\sim 3$ times higher volumetric energy density. However, the potential of a formic acid fuel cell is high; even a few hundred millivolts reduction in overpotential can allow formic acid to output energy than methanol per molecule.

Key to the formic acid oxidation is the direct link to the reverse electrochemical reaction, i.e. the $\mathrm{CO}_{2}$ reduction reaction $\left(\mathrm{CO}_{2} \mathrm{RR}\right){ }^{7,8}$ Combining these two reactions allows for a closed carbonloop with formic acid working as a liquid energy storage media. $\mathrm{CO}_{2} \mathrm{RR}$ to formic acid and the formic acid oxidation reaction (FAOR) can be written in the form:

$$
\begin{array}{lll}
\left(\mathrm{CO}_{2} \mathrm{RR}\right) & \mathrm{CO}_{2}+2 \mathrm{H}^{+}+2 e^{-} \rightarrow \mathrm{HCOOH} & , \Delta G_{\mathrm{CO}_{2} \rightarrow \mathrm{HCOOH}}^{0}=0.12 \mathrm{eV} \text { per } \mathrm{H}^{+}+e^{-} \\
(\mathrm{FAOR}) & \mathrm{HCOOH} \rightarrow \mathrm{CO}_{2}+2 \mathrm{H}^{+}+2 e^{-} & , \Delta G_{F A O R}^{0}=-0.12 \mathrm{eV} \text { per } \mathrm{H}^{+}+e^{-}
\end{array}
$$

Where $\Delta G^{0}$ is the thermodynamic potential per proton-electron pair of the reaction.

$\mathrm{CO}_{2} \mathrm{RR}$ selectivity is highly dependent on the catalyst material used and the crystal orientation. ${ }^{9-}$ 1112 Hori et al. showed that hydrogen is produced on $\mathrm{Pt}, \mathrm{Ru}, \mathrm{Fe}$ and $\mathrm{Ni}$, carbon monoxide is produced on $\mathrm{Au}, \mathrm{Ag}, \mathrm{Zn}, \mathrm{Ga}$ and $\mathrm{Pd}$ (which also produces similar amounts of $\mathrm{H}_{2}$ ), and finally, formic acid is produced on $\mathrm{Pb}, \mathrm{In}, \mathrm{Hg}, \mathrm{Sn}, \mathrm{Cd}$ and $\mathrm{Tl} .{ }^{12}$ Importantly, hydrocarbons are uniquely produced on $\mathrm{Cu}^{12}$ Using simulations, we were able to classify the $\mathrm{CO}_{2} \mathrm{RR}$ product distributions towards hydrogen, hydrocarbons, $\mathrm{CO}$ and formic acid due to the catalyst's affinity towards adsorbed ${ }^{*} \mathrm{H}$ and ${ }^{*} \mathrm{CO} .{ }^{10}$ Interestingly, we hereto noted that the $\mathrm{CO}_{2} \mathrm{RR}$ propensity towards formic acid generally appears to be more selective when weakening * $\mathrm{H}$ binding, or in other words; $\mathrm{CO}$ is favored over $\mathrm{HCOOH}$ when catalyst binds ${ }^{*} \mathrm{H}$ sufficiently strong without forming $\mathrm{H}_{2}$. Moreover, from this study ${ }^{10}$ we noted that the ${ }^{*} \mathrm{OOCH}$ vs. the ${ }^{*} \mathrm{COOH}$ intermediate cannot be used to 
distinguish the $\mathrm{CO}$ or formic acid product formation. These findings are readily usable when considering the reverse reaction FAOR.

FAOR exhibits the highest intrinsic pure metal activity on Pt and $\mathrm{Pd} .{ }^{8,13,14}$ However, the reaction is affected by high overpotentials and formation of various poisoning intermediates. ${ }^{15}$ The following observations can be made in the literature, as shown in Supporting information (SI) Figure S1: (i) FAOR onsets at low potentials does not necessarily correspond to high FAOR currents. (ii) Hysteresis between anodic and cathodic scans is a common occurrence. (iii) $\operatorname{Pt}(111)$ is more active than $\operatorname{Pd}(100)$ in the low overpotential region; however, interestingly, this relationship shifts at higher potentials. (iv) As an observation it is known that there is a difference for Pt and Pd with respect to the $\mathrm{CO}$ poisoning during $\mathrm{FAOR}^{8}$. The ideal FAOR catalyst on the other hand should show reversible cyclic voltammetry (CV), high activity, low onset potential and stable currents, as illustrated in Figure S2.

To understand the mechanism of this important reaction numerous attempts have been made to map possible FAOR pathways, ${ }^{15-19}$ which we illustrate by an in-depth literature study in Figure 1. The motivation has often been the elucidation of the reaction mechanism along with the identification and circumvention of poisoning issues. Either through pathway engineering, ${ }^{16,17}$ changing electrolyte composition, ${ }^{18}$ or inclusion of sites with the ability to remove poisoning species. ${ }^{19-22}$ CO-poisoning from partial $\mathrm{HCOOH}$ oxidation is often considered the principal culprit $^{20}$ and various works suggest $\mathrm{CO}$ formation can be avoided utilizing a single/dual-site catalyst. ${ }^{23-26}$ However, catalysts such as $\mathrm{Au}-\mathrm{Pt},{ }^{16} \mathrm{Pt}-\mathrm{Hg} / \mathrm{C}^{27}$ and $\mathrm{Pd}-\mathrm{Hg} / \mathrm{C}^{28}$ exhibit limited catalytic improvement over their pure metal counterparts, for some overview see Figure S4 in SI. 


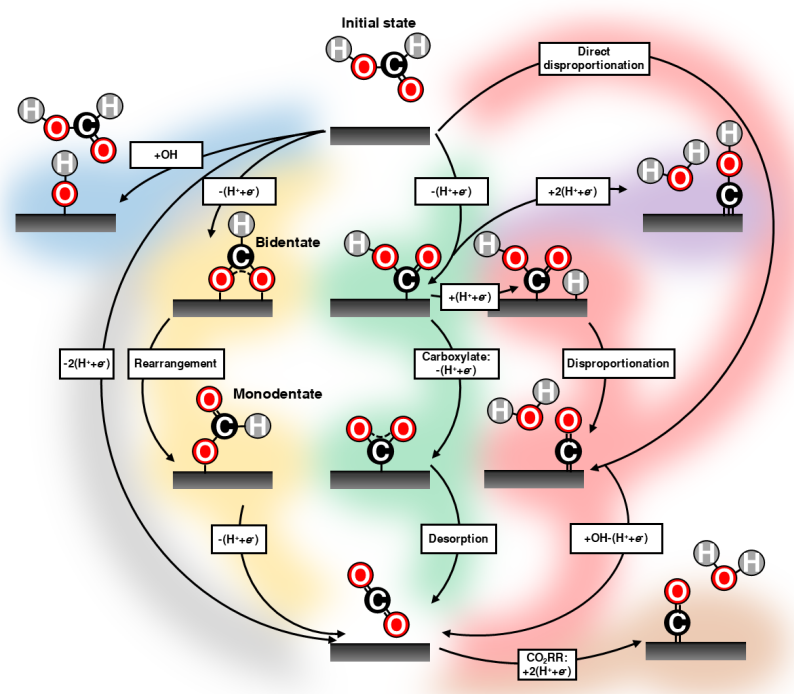

Figure 1. Literature study highlighting all the conceived FAOR reaction pathways during potential cycling. ${ }^{29}$ Historically, FAOR has been split into the direct (gray) ${ }^{30,31}$ and indirect (green and

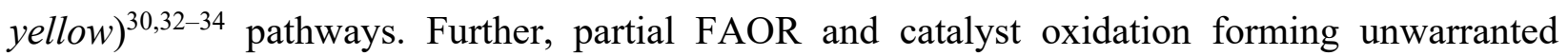
surface blocking have been suggested, e.g. $\mathrm{CO}_{x} \mathrm{H}_{y}$ species (purple), ${ }^{15,35,36} \mathrm{CO}$ (red) ${ }^{37}$ and hydroxide/oxides $(\text { blue })^{29}$. Even $\mathrm{CO}_{2} \mathrm{RR}$ induced $\mathrm{CO}$ formation by applying too cathodic potential $(\text { brown })^{31}$ have been suggested. Recently, formate $(\text { yellow })^{20,30,38,39}$ in various arrangements has gained attention as potential catalyst poisons.

In this work, we address the fundamental questions in FAOR:

(i) Does FAOR proceed through ${ }^{*} \mathrm{COOH}$ or ${ }^{*} \mathrm{OOCH}$ ?

(ii) How is $\mathrm{CO}$ formed during FAOR?

(iii) $\mathrm{Can}{ }^{*} \mathrm{OOCH}$ act as both a spectator and a poisoning species? ? $^{40-42}$

(iv) Why do only few catalysts work for FAOR? 
While Figure 1 treats all the proposed FAOR reaction paths uncritically, Figure 2 summarizes the minimum number of considerations we believe is required to understand the FAOR process qualitatively.

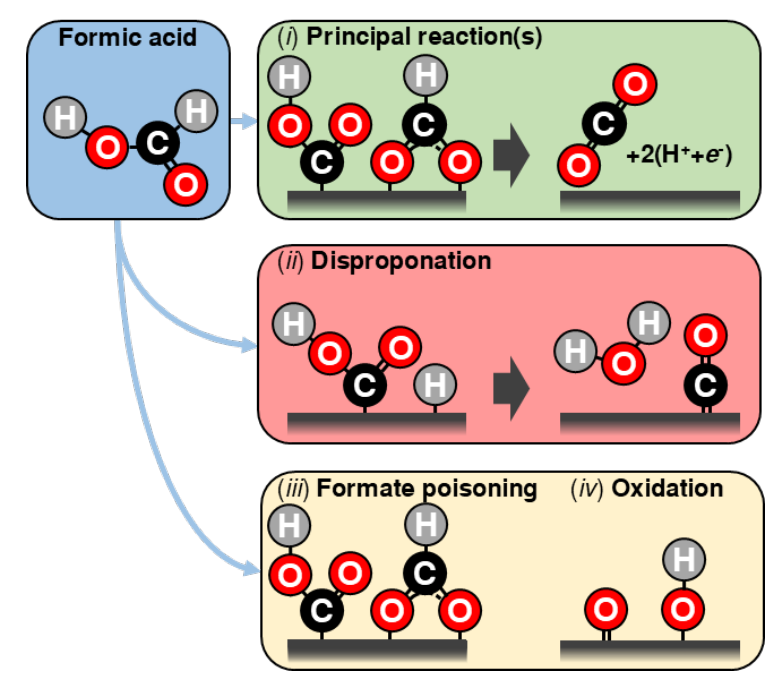

Figure 2. Presentation of the minimum reaction elements required to understand FAOR activity and the poisoning events potentially occurring during CVs, based on Figure S3 in the SI.

The important aspects for FAOR highlighted in Figure 2 are (i) the principal reaction through ${ }^{*} \mathrm{COOH}$, (ii) the disproponation reaction of ${ }^{*} \mathrm{COOH}$ reacting with ${ }^{*} \mathrm{H}$ to form $\mathrm{CO}$, (iii) formate poisoning via ${ }^{*} \mathrm{OOCH}$ and (iv) oxidation of the catalysts. Considerations of the reactions $(i)$ and (iv) is of common occurrence in FAOR literature. While in this work, we consider and analyze (ii) and (iii) based on FAOR's strong link to the $\mathrm{CO}_{2} \mathrm{RR} .{ }^{10}$ To the best of our knowledge, the disproportionation reaction (ii) is only anecdotally mentioned in the comprehensive work of Sun et al. on Pt. ${ }^{29}$ In contrast, it has been widely accepted in $\mathrm{CO}_{2} \mathrm{RR}$ literature that protonating ${ }^{*} \mathrm{COOH}$ leads to $\mathrm{CO}^{43}$ For $\mathrm{CO}_{2} \mathrm{RR}$ it has been a paradox that formate $\left({ }^{*} \mathrm{OOCH}\right)$ binds stronger than carboxyl $\left({ }^{*} \mathrm{COOH}\right)$. Hence, while carboxyl describes the onset potential for $\mathrm{CO}$ formation the 
formate species does not correlate with any $\mathrm{CO}_{2} \mathrm{RR}$ reaction activity and is consequently considered a $\mathrm{CO}_{2} \mathrm{RR}$ poison. ${ }^{44}$

To probe the scientific questions, we use a combination of experimental and simulation tools.

For experiments we use cyclic voltammetry (CV) and chronoamperometric (CA). For simulations we use density functional theory (DFT) calculations on the binding of carboxyl, ${ }^{*} \mathrm{COOH}$, formate bidentate, ${ }^{*} \mathrm{OOCH}$, and hydrogen, ${ }^{*} \mathrm{H}$.

\section{Results and Discussion}
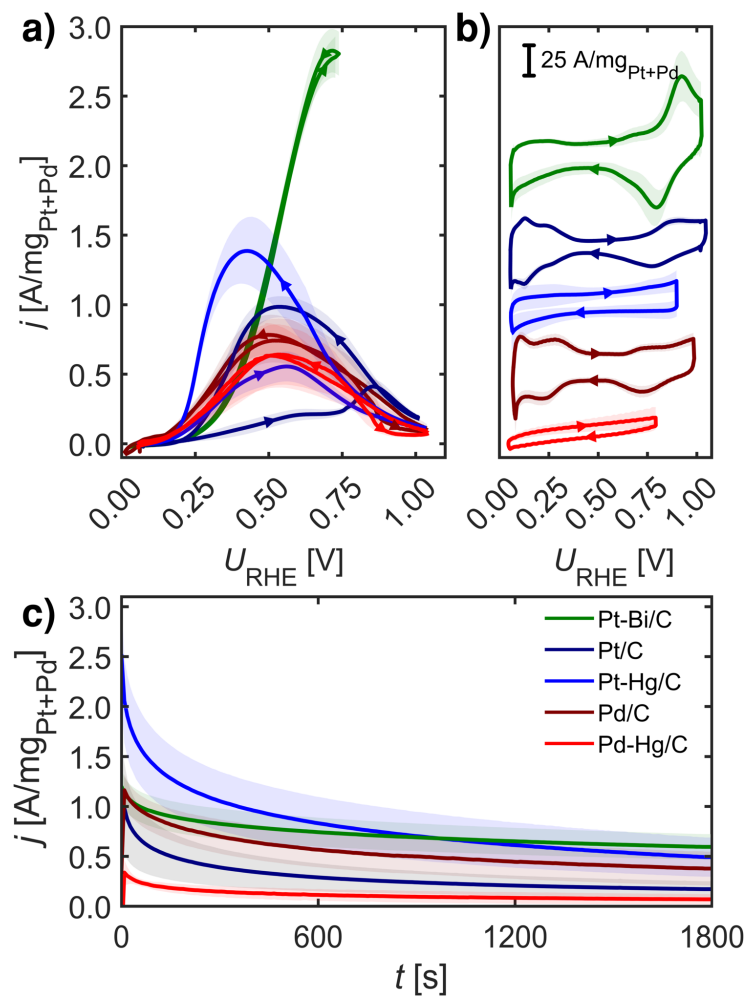

Figure 3. Electrochemical data recorded at room temperature of equal loading nanoparticle catalysts: Pt/C (navy blue), $\mathrm{Pd} / \mathrm{C}$ (crimson), $\mathrm{Pt}-\mathrm{Hg} / \mathrm{C}$ (blue), $\mathrm{Pd}-\mathrm{Hg} / \mathrm{C}$ (red) and Pt-Bi/C (green) systems on glassy carbon in Ar-saturated $0.1 \mathrm{M} \mathrm{HClO}_{4}$ with $0.1 \mathrm{M} \mathrm{HCOOH}$ at $1600 \mathrm{rpm}$, unless 
otherwise stated. (a) FAOR CVs at $10 \mathrm{mV} / \mathrm{s}$. (b) Base CVs in Ar-saturated $0.1 \mathrm{M} \mathrm{HClO}_{4}$ at 400 rpm and $50 \mathrm{mV} / \mathrm{s}$. (c) $\mathrm{CA}$ at $0.55 \mathrm{~V}_{\mathrm{RHE}}$ for $30 \mathrm{~min}$. All measurements were repeated at least three times (shade represents standard deviation), $I R$-compensated and post-corrected, for experimental details see SI and Figure S5-S8.

Figure 3 summarizes experimental electrochemical data of $\mathrm{Pt} / \mathrm{C}, \mathrm{Pd} / \mathrm{C}, \mathrm{Pt}-\mathrm{Hg} / \mathrm{C}, \mathrm{Pd}-\mathrm{Hg} / \mathrm{C}$ and $\mathrm{Pt}-\mathrm{Bi} / \mathrm{C}$. Here we investigate only known and active FAOR catalyst, and both extended surfaces as $\mathrm{Pt} / \mathrm{C}$ and $\mathrm{Pd} / \mathrm{C}$, but also single site catalyst $\mathrm{Pt}-\mathrm{Hg} / \mathrm{C}$ and $\mathrm{Pd}-\mathrm{Hg} / \mathrm{C}$ and the noteworthy very active $\mathrm{Pt}-\mathrm{Bi} / \mathrm{C}$ system. Figure $3 \mathrm{a}$ shows the formic acid oxidation $\mathrm{CV}$ during rotation and $10 \mathrm{mV} / \mathrm{s}$ scanrate on the five catalysts. Figure $3 \mathrm{~b}$ depicts the base CVs exhibiting suppressed hydrogen underpotential deposition (HUpD) on the $\mathrm{Pt}-\mathrm{Bi} / \mathrm{C}, \mathrm{Pt}-\mathrm{Hg} / \mathrm{C}$ and $\mathrm{Pd}-\mathrm{Hg} / \mathrm{C}$ compared to the $\mathrm{Pd} / \mathrm{C}$ and $\mathrm{Pt} / \mathrm{C}$ counterparts. Figure $3 \mathrm{c}$ displays the formic acid oxidation $\mathrm{CA}$ at $0.55 \mathrm{~V}_{\mathrm{RHE}}$ for $30 \mathrm{~min}$, illustrating the loss in activity at this potential due to the formation of poisoning or blocking species. For Pt $/ \mathrm{C}$ and Pt-Hg/C, an apparent hysteresis is seen in the oxidation between the forward and backward scans of Figure 3a indicating an irreversible change in the catalyst going to low potentials. Interestingly, taking a combined view on Figure 3a,c shows that forming single-sites of Pt through $\mathrm{Hg}$ alloying 27,28 tend to improve the FAOR onset. In contrast, Pd-based catalysts generally do not exhibit any hysteresis. The Pt-Bi/C system exhibit the highest FAOR current with least hysteresis, but also with the highest overpotential. Additional relevant electrochemical studies can be found in the SI, represented through Figures S10-S14. To make sense of all of these observations we turned to DFT. 

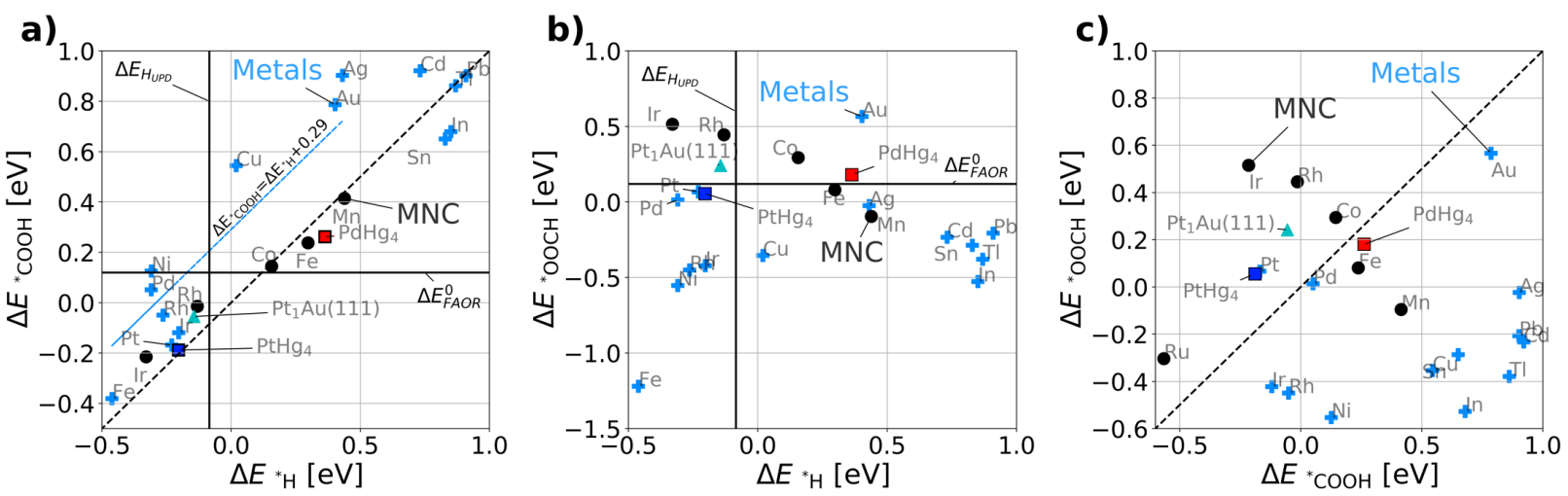

Figure 4. DFT calculated binding energies for metal (111) fcc (light-blue crosses) and singlesite catalyst. MNC-based (black points), $\mathrm{Pt}$ atom in $\mathrm{Au}(111)$ denoted $\mathrm{Pt}_{1} \mathrm{Au}(111)$ (cyan triangle), $\mathrm{PdHg}_{4}$ (black/red square) and $\mathrm{PtHg}_{4}$ (black/blue square). (a) ${ }^{*} \mathrm{COOH}$ vs. ${ }^{*} \mathrm{H}$. (b) ${ }^{*} \mathrm{OOCH}$ vs. ${ }^{*} \mathrm{H}$. (c) ${ }^{*} \mathrm{OOCH} v s .{ }^{*} \mathrm{COOH}$, here the dashed line shows the diagonal indication the affinity towards formate bound through carbon or oxygen. Here its assumed $\Delta E_{F A O R}^{0} \approx \Delta G_{F A O R}^{0}$. Further, we used $\mathrm{CO}_{2}$ and $\mathrm{H}_{2}$ for references when calculating ${ }^{*} \mathrm{COOH}, \Delta E_{F A O R}^{0}$ is $0.12 \mathrm{eV}$ per electron.

Figure 4a maps out the DFT calculated ${ }^{*} \mathrm{COOH} v s .{ }^{*} \mathrm{H}$ binding energies of the most relevant metals and single-site catalysts, such as $\mathrm{MNCs}, \mathrm{PtHg}_{4},{ }^{27} \mathrm{PdHg}_{4}{ }^{28}$ and single $\mathrm{Pt}$ atoms in $\mathrm{Au}$, $\mathrm{Pt}_{1} \mathrm{Au}(111)^{16}$. For metals and the single-site-catalysts linear scaling appears: $\Delta E *_{\mathrm{COOH}}=\Delta E *_{\mathrm{H}}+b$, where $b$ is about $0.29 \mathrm{eV}$ as previously ${ }^{45}$ observed for metals and $0.0 \mathrm{eV}$ for single-site catalyst, respectively. Besides the scaling, a vertical- and a horizontal line indicating $\mathrm{H}_{\mathrm{UPD}}\left(\Delta E_{\mathrm{H}_{\mathrm{UPD}}}\right)$ and formic acid's thermodynamic equilibrium potential have been included in Figure 4a,b. Here its assumed that $\Delta E_{F A O R}^{0} \approx \Delta G_{F A O R}^{0}$, as thermodynamic corrections and water stabilization are expected to cancel out for the ${ }^{*} \mathrm{COOH}$ intermediate. The fundamental scaling between ${ }^{*} \mathrm{COOH}$ and ${ }^{*} \mathrm{H}$, together with the potential adsorption of ${ }^{*} \mathrm{H}$ on the surface, leads to the possibility of disproportionation towards $\mathrm{CO}$. This entails that crossing the scaling and the HUPD line represents a fundamental limit for the binding of ${ }^{*} \mathrm{COOH}$ at $0.2 \mathrm{~V}_{\mathrm{RHE}}$ for metals to avoid disproportionation. 
Figure $4 \mathrm{~b}$ displays the DFT calculated binding energies of ${ }^{*} \mathrm{OOCH}$ vs. ${ }^{*} \mathrm{H}$. Conversely to Figure 4a, there is no apparent scaling between formate bidentate and adsorbed hydrogen (however the oxygen bond for ${ }^{*} \mathrm{OOCH}$ scales with $\left.{ }^{*} \mathrm{OH}\right)$. Essentially, Figure $4 \mathrm{~b}$ shows that the FAOR pathway cannot follow the ${ }^{*} \mathrm{OOCH}$ intermediate. Comparing the data of Figure $4 \mathrm{~b}$ with literature one can observe that metal catalysts, such as $\mathrm{Cu}$ and $\mathrm{Ag}$ exhibiting a short distance to the equilibrium potential line - meaning that they should be active - are not active for the FAOR in experimental investigations (also shown in Figure S10). In short, it is unlikely that *OCH is an important reaction intermediate. Instead, given that the ${ }^{*} \mathrm{OOCH}$ scales with ${ }^{*} \mathrm{OH}$, the ${ }^{*} \mathrm{OOCH}$ binding can be considered a probe of the oxidation affinity of the catalyst, i.e. having a strong *OCH binding results in a lower oxidation potential.

Figure $4 \mathrm{c}$ shows the ${ }^{*} \mathrm{OOCH} v s .{ }^{*} \mathrm{COOH}$ binding for the catalyst, with a dashed line indicating the affinity towards carbon or oxygen bound formate. Depending on the catalyst we can see whether formate bidentate or carboxyl is favored. In this regard there is a small caveat, that *OCH scales with ${ }^{*} \mathrm{OH}$ binding, as discussed above. Figure 4c further reveals that most pure metal catalyst, e.g. $\mathrm{Ir}^{46}$ or $\mathrm{Au}^{47}$, should perform poorly as FAOR catalyst in agreement with the literature. Only two outliers exist for this interpretation, that is $\mathrm{Pd}^{13}$ and $\mathrm{Rh}^{48}$. However, $\mathrm{Pd}^{*} \mathrm{OOCH}$ binding is too close to that of ${ }^{*} \mathrm{COOH}$ disallowing specific conclusions on that element. Moreover, consulting Rh's Pourbaix diagram ${ }^{49}$ the divergence from our hypothesis is explained by the formation of conductive oxides forming in the FAOR relevant $\mathrm{pH}$ - and potential conditions.

The type of analysis illustrated in Figure 4 is an powerful tool able to identify which catalyst suffers from disproportionation and, by virtue of the scaling-relations, ${ }^{10}$ it gives fundamental insights into why literature historically has shown no significant FAOR activity below $\sim 0.2 \mathrm{~V}$ RHE for a metal catalysts. By trusting Figure $4 \mathrm{a}$ as a the principal design guide governing FAOR 
activity, it even suggests that, to achieve FAOR activities below $0.2 \mathrm{~V}_{\mathrm{RHE}}$, one needs to consider single-site-based catalyst as the ${ }^{*} \mathrm{COOH} v s .{ }^{*} \mathrm{H}$ scaling is shifted $c a .0 .29 \mathrm{eV}$ weaker compared to metal-based catalysts. Implicitly Figure 4a states that hysteresis between anodic and cathodic sweeps in FAOR CVs arise due to this type of disproportionation occurring at low potential arising from the HUPD and the consequent creation of ${ }^{*} \mathrm{CO}$ poisoning species. From this insight, one would expect that disproportionation is mitigated in the CVs by simply staying above HuPD potentials.

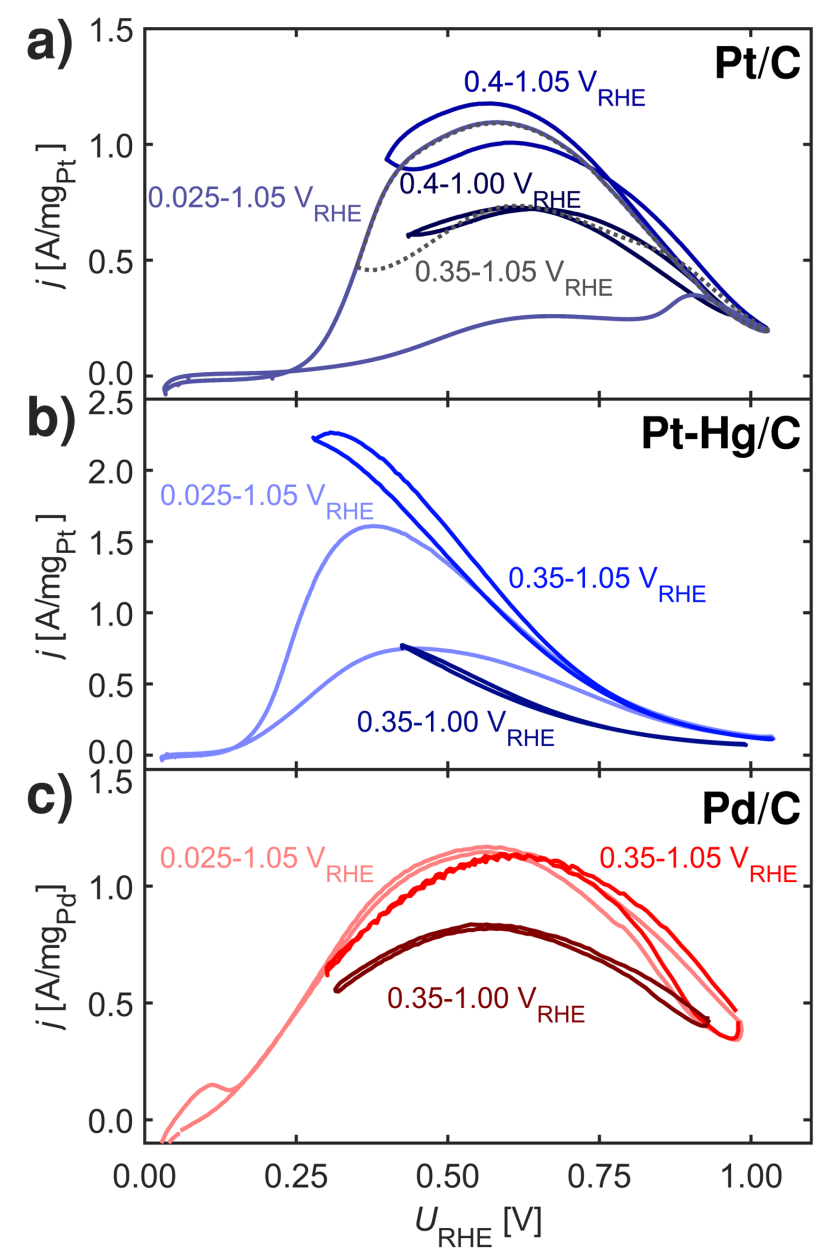

Figure 5. FAOR CVs at $10 \mathrm{mV} / \mathrm{s}, 1600 \mathrm{rpm}$ and room temperature in Ar-saturated $0.1 \mathrm{M} \mathrm{HClO}_{4}$ with $0.1 \mathrm{M} \mathrm{HCOOH}$ at different potential limits. Ohmic drops were post-corrected. (a) Pt/C. (b) Pt-Hg/C. (c) Pd/C. Note, increasing lower potential limit minimizes the hysteresis in the CVs, lowering the upper potential limit generally decreases the activity. 
Figure 5 shows the performance of $\mathrm{Pt} / \mathrm{C}, \mathrm{Pt}-\mathrm{Hg} / \mathrm{C}$ and $\mathrm{Pd} / \mathrm{C}$ cycled with varying potential limits. The potential range from $0.00-1.05 \mathrm{~V}_{\mathrm{RHE}}$ reveals that $\mathrm{Pt} / \mathrm{C}$ and $\mathrm{Pt}-\mathrm{Hg} / \mathrm{C}$ are poisoned in anodic sweeps. Changing to potentials, ranging from $0.40-1.05 \mathrm{~V}_{\mathrm{RHE}}$ for the $\mathrm{Pt} / \mathrm{C}$ and $0.35-1.05 \mathrm{~V}_{\mathrm{RHE}}$ for the $\mathrm{Pt}-\mathrm{Hg} / \mathrm{C}$, significantly increases the anodic activity. Hence, this allows us to prove that $\mathrm{H}_{\mathrm{UPD}}$ mediated disproportionation account for poisoning through $\mathrm{CO}$ on Pt catalysts. For $\mathrm{Pd} / \mathrm{C}$ in Figure $5 \mathrm{c}$, decreasing the lower potential limit has no influence on the almost non-existing FAOR hysteresis. In this context, it is important to note that Pd is well-known to form Pd-hydride phases ${ }^{50}$ below $0.2 \mathrm{~V}_{\mathrm{RHE}}$, i.e. at potentials relevant for both $\mathrm{FAOR}$ and $\mathrm{CO}_{2} \mathrm{RR}$. In relation to $\mathrm{CO}_{2} \mathrm{RR}$, we also note that Pd-hydride, leads to a high faradaic efficiency towards formate, ${ }^{51}$ whereas at higher overpotentials $\mathrm{CO}$ and $\mathrm{H}_{2}$ will dominate ${ }^{12}$.

Concerning Figure 5, one could erroneously assume that lowering the upper potential limit would not affect the CVs, while staying above the $\mathrm{CO}$ oxidation potential. This is however not the case, cycling 50 times from $0.35-1.00 \mathrm{~V}_{\mathrm{RHE}}$ reveals some form of deactivation of both $\mathrm{Pt} / \mathrm{C}, \mathrm{Pt}-$ $\mathrm{Hg} / \mathrm{C}$ and $\mathrm{Pd} / \mathrm{C}$. We do not know what the origin of this deactivation is. Various studies reported in the literature suggests different reasons including deactivation to irreversible metal oxidation ${ }^{52,53}$ due to insufficient surface reduction or accumulation of either ${ }^{*} \mathrm{OOCH}^{54},{ }^{*} \mathrm{COH},{ }^{29}{ }^{*} \mathrm{OCOH}^{55}$ or ${ }^{*} \mathrm{CO}$ species. Most interesting is that in situ Fourier-transform infrared spectroscopy (FTIR) work $^{42,56}$ has shown that $\mathrm{Pt}$, contrary to Pd, continuously form CO above HuPD potential during FAOR.

To gauge how the FAOR is affected in the potentials regions above $\mathrm{H}_{\text {UPD }}$ we conducted pulsed voltammetry inspired by Clavilier et al. ${ }^{57}$ In this type of pulsed voltammetry experiments, each potential investigated is separated by a surface re-initialization (at $1.05 \mathrm{~V}_{\mathrm{RHE}}$ ) cleaning the surface 
for all poisons through surface oxidation. The impact from dissolution at this oxidizing potential should be minimal. ${ }^{58,59}$

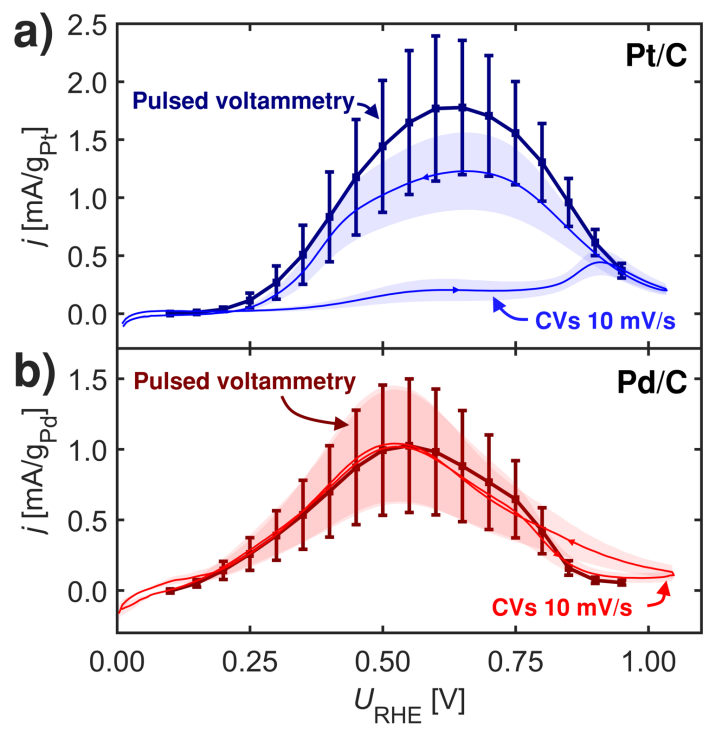

Figure 6. $2 \mathrm{~s}$ pulsed voltammetry and CVs at $10 \mathrm{mv} / \mathrm{s}$ at room-temperature at $1600 \mathrm{rpm}$ in Arsaturated $0.1 \mathrm{M} \mathrm{HClO}_{4}$ with $0.1 \mathrm{M} \mathrm{HCOOH}$. (a) Pt/C. (b) Pd/C. Measurements repeated three times.

Figure 6 shows pulsed voltammograms and corresponding $\mathrm{CVs}$ for $\mathrm{Pt} / \mathrm{C}$ and $\mathrm{Pd} / \mathrm{C}$ samples. It appears that only $\mathrm{Pt} / \mathrm{C}$ 's activity isby the pulses, indicative of poisoning at potentials above those associated with the $\mathrm{H}_{\mathrm{UPD}}$ induced disproportionation to $\mathrm{CO}$. In contrast, $\mathrm{Pd} / \mathrm{C}$ does not show any changes from the pulsing. Essentially, these results suggests that the ${ }^{*} \mathrm{COOH} v s .{ }^{*} \mathrm{OOCH}$ formate map is a poor descriptor for identifying, which catalysts are likely to be poisoned by non-CO species during FAOR. We believe this warrants a careful mention, to discourage future misinterpretations: It seems catalyst favoring ${ }^{*} \mathrm{COOH}$ over ${ }^{*} \mathrm{OOCH}$ performs better during FAOR above $\mathrm{H}_{\mathrm{UPD}}$ potentials but assigning this to an effect of surface poisoning by ${ }^{*} \mathrm{OOCH}$ is neither supported from our experiments (additionally see Figure S9) or the literature ${ }^{42,56}$. 
In general, in a selective two-electron reaction a single intermediate binding energy should be sufficient to describe the reaction, as it is the case of hydrogen evolution or oxidation reaction (HER or HOR). Contrary, selective multi-electron reactions require more intermediates, as it is the case for oxygen evolution and oxygen reduction reaction (OER and ORR). Unfortunately, the traditional tool to gauge activity — the theoretical volcano plot — applicability is challenged when considering hetero-selective reactions. Given that the FAOR is a two-electron reaction, it should ideally have only one important intermediate. However, due to the unwanted side reactions - the disproportionation towards $\mathrm{CO}-$ this is not the case. From a theoretical perspective, this means that a FAOR volcano can be drawn, but never truly probed in experiments, as the volcano will encompass regions where competitive disproportionation dominates. Instead, we can probe the energetic conditions allowing for ${ }^{*} \mathrm{COOH}$ adsorption/desorption while avoiding $\mathrm{H}_{\mathrm{UPD}}$, which allow us to draw an active catalyst area, at various potentials where selective $\mathrm{FAOR}$ towards $\mathrm{CO}_{2}$ occur, see Figure 7. 


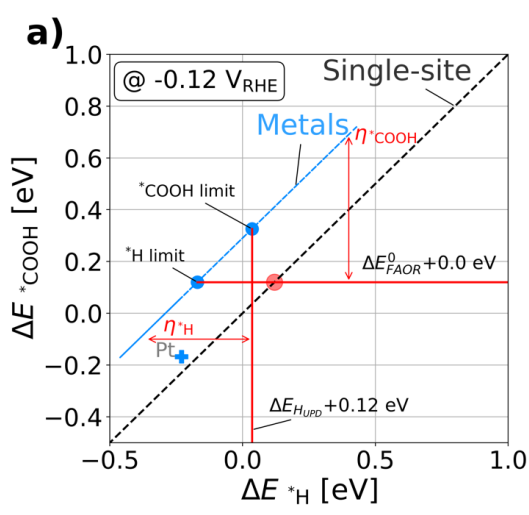

d)
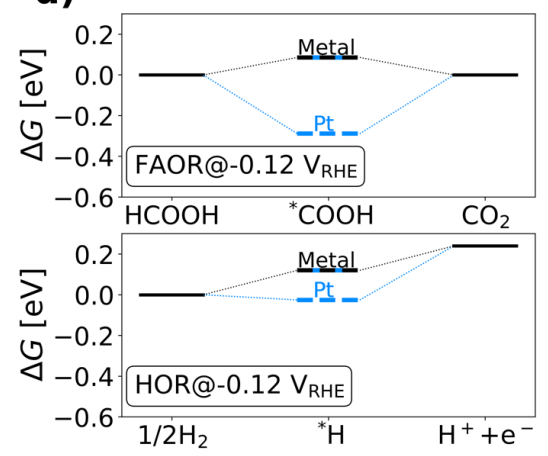

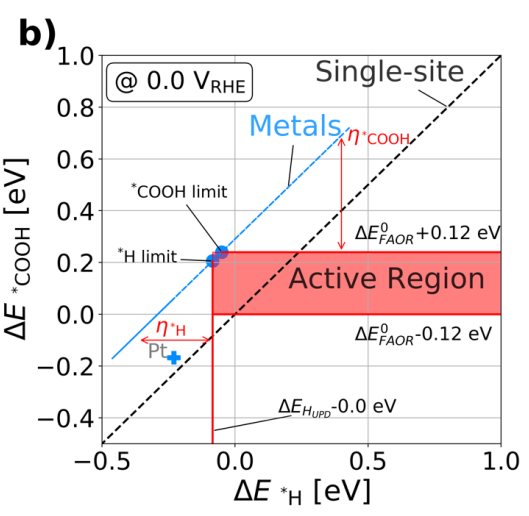

e)
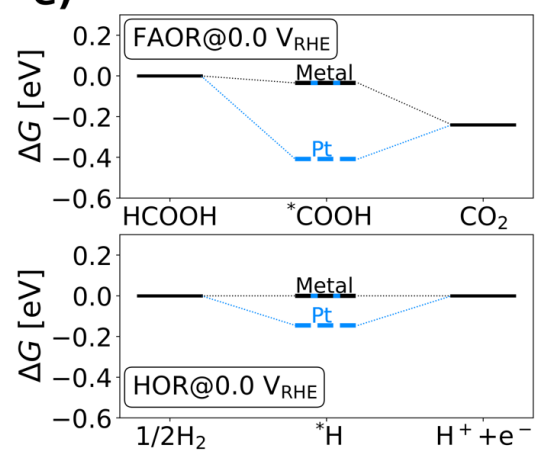

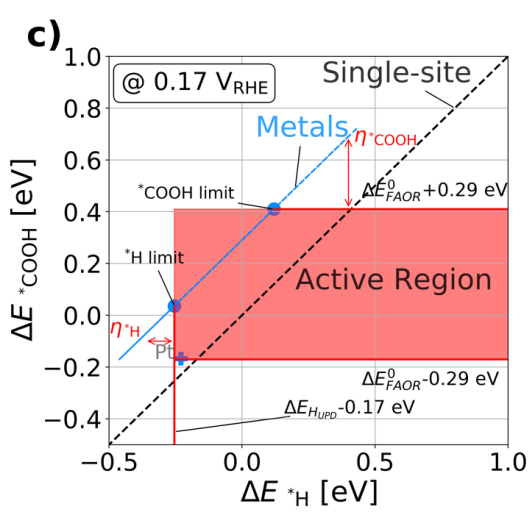

f)
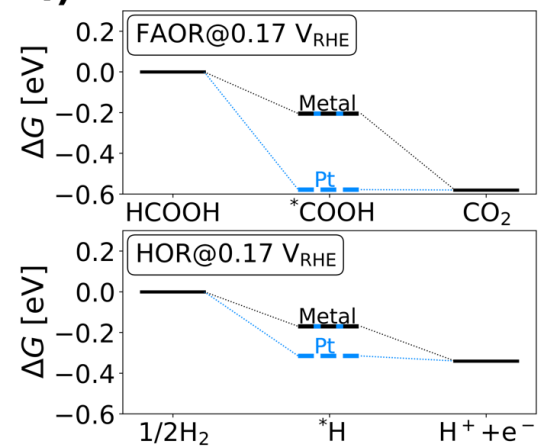

Figure 7. Energetic considerations of FAOR. (a-c) ${ }^{*} \mathrm{COOH} v s .{ }^{*} \mathrm{H}$ binding energy maps, with the scaling of the metals (light-blue) and single-sites (black) and the platinum catalyst (light-blue cross). The horizontal and vertical line denotes FAOR and HOR equilibriums when applying a potential. Both lines moves correspondingly when applying a potential, outlining an area where active catalyst avoid CO disproportionation. (d-f) Corresponding free energy diagrams of (a-c) for FAOR and HOR for the optimal metal catalyst using the metal scaling (black/light-blue) and the platinum catalyst (light-blue) when applying a different potential. In (a-f) the potentials selected are the FAOR equilibrium potential $\left(-0.12 \mathrm{~V}_{\mathrm{RHE}}\right)$, HOR equilibrium potential $\left(0.0 \mathrm{~V}_{\mathrm{RHE}}\right)$ and the limiting potential on $\mathrm{Pt}\left(0.17 \mathrm{~V}_{\mathrm{RHE}}\right)$.

Figure 7 combines the fundamental findings limiting the FAOR. Figure $7 \mathrm{a}-\mathrm{c}$ show the ${ }^{*} \mathrm{COOH} v s$. ${ }^{*} \mathrm{H}$ binding energy where the horizontal and vertical line depict the FAOR and HOR equilibrium at three relevant potentials, respectively. Once potentials above the equilibriums are applied, an 
energetic area (shaded red) defining the conditions in which active and selective catalysts can be found. Using the metal scaling, Figure $7 \mathrm{~d}-\mathrm{f}$ shows the corresponding free energy diagrams for FAOR and HOR, for the optimal metal catalyst and $\mathrm{Pt}$ at relevant potentials. Three potentials were deemed relevant, that is; the FAOR equilibrium potential ( $\left.-0.12 \mathrm{~V}_{\mathrm{RHE}}\right)$, the RHE potential $(0.0$ $\left.\mathrm{V}_{\mathrm{RHE}}\right)$ and the limiting potential at $\mathrm{Pt}\left(0.17 \mathrm{~V}_{\mathrm{RHE}}\right)$.

Figure 7a-c highlights that there are three limiting potentials important when considering FAOR electrocatalysis: $(i)$ The weak binding of ${ }^{*} \mathrm{COOH}$ binding governing the possible FAOR onset. (ii) The strong binding of ${ }^{*} \mathrm{H}$, imposing possible $\mathrm{CO}$ disproportionation and/or HER. (iii) Active FAOR limitations imposed by the applied potential in relation to, too strong binding of ${ }^{*} \mathrm{COOH}$, governing ${ }^{*} \mathrm{COOH}$ retention on the catalyst surface during FAOR.

Figure $7 \mathrm{~d}$-f suggest that the optimal metal catalyst found on the ${ }^{*} \mathrm{COOH} v s .{ }^{*} \mathrm{H}$ scaling, although having a ${ }^{*} \mathrm{COOH}$ binding facilitating FAOR at relevant potentials, will be limited by having ${ }^{*} \mathrm{H}$ on the surface until $\sim 0.0 \mathrm{~V}_{\mathrm{RHE}}$. This can interpreted as: ${ }^{*} \mathrm{H}$ will always bind to the surface when the energy level of $\left(\mathrm{H}^{+}+e^{-}\right)$is above ${ }^{*} \mathrm{H}$. Hence, a working catalyst should favor ${ }^{*} \mathrm{H}$ binding weaker than $\left(\mathrm{H}^{+}+e^{-}\right)$not to be limited by disproportionation. This interpretation form the basis of a theoretical FAOR overpotential, $\eta=0.12 \mathrm{eV}$. Figure 7 also suggests that platinum generally is limited due to being too reactive toward hydrogen and consequently explain all the Pt-based FAOR literature discussed here and in the SI.

A final note should be made concerning the analysis in Figure 4 and 7 . The interpretation and data strongly suggest that a single-site Co-MNC catalyst should not be restricted by ${ }^{*} \mathrm{H}$, whilst having a nearly ideal ${ }^{*} \mathrm{COOH}$ binding value. In total Co-MNCs should work as an efficient catalyst for FAOR near its equilibrium potential, assuming the Co-MNC is stabile under acidic conditions. 


\section{Conclusion}

In conclusion we have shown the fundamental limitations of FAOR and used this to derive the underlying volcano. We have observed that for an ideal catalyst, the FAOR equilibrium potential should be above its corresponding HUPD potential in order to avoid the disproportionation. Additionally, such catalyst should have an optimal * $\mathrm{COOH}$ binding and is suggested to generally favor ${ }^{*} \mathrm{COOH}$ over ${ }^{*} \mathrm{OOCH}$. We found that ${ }^{*} \mathrm{COOH}$ and ${ }^{*} \mathrm{H}$ binding scale on both metal and singlesite catalysts. This creates the fundamental limitation of either too weak ${ }^{*} \mathrm{COOH}$ resulting in a high overpotential or limiting potential due to $\mathrm{H}_{\mathrm{UPD}}$ mediated disproportionation on the surface. The carbon - hydrogen scaling is indeed a fundamental limitation, analog to the * $\mathrm{OH}$ and ${ }^{*} \mathrm{OOH}$ scaling for oxygen evolution and reduction. Experimentally, we show that a good performing FAOR catalyst should have the attributes of; $(i)$ a close to the fundamental derived onset, (ii) no hysteresis between anodic- and cathodic CV scans and (iii) high and stable FAOR CA currents above the derived onsets fundamental limits. Attributes $(i-i i i)$ can all be achieved considering the ${ }^{*} \mathrm{COOH} v s$. ${ }^{*} \mathrm{H}$ map or volcano, Figure $4 \mathrm{a}$ and $5 \mathrm{~b}$, respectively.

\section{ASSOCIATED CONTENT}

Supporting Information. The Supporting Information is available free of charge on the ACS Publications website at DOI: XXXXXXX. Relevant aspects of the computational model and methods and the experimental methodology are included herein. (PDF). Additionally, atomic structures and analysis scripts are available on the webpage:

https://chem.ku.dk/research_sections/nanochem/theoretical-electrocatalysis/ 


\section{AUTHOR INFORMATION}

\section{Corresponding Author}

*alexander@chem.ku.dk

\section{ORCID:}

Jan Rossmeisl: 0000-0001-7749-6567

Kim D. Jensen: 0000-0001-7466-8458

María Escudero-Escribano: 0000-0002-6432-3015

Alexander Bagger: 0000-0002-6394-029X

Maryam Rashedi: 0000-0002-8927-2955

Rui Luo: 0000-0002-5425-0043

Jia Du: 0000-0002-2387-1912

Damin Zhang: 0000-0002-9037-6778

Inês J. Pereira: 0000-0002-6992-6472

Mathias Arenz: 0000-0001-9765-4315

\section{Author Contributions}

The manuscript was written through contributions of all authors. All authors have given approval to the final version of the manuscript. These authors contributed equally. K.D.J. conceptualized experiments with the aid of M.A., M.E.-E., J.D. and D.Z. and conducted the majority of the experiments with the aid of M.R. and I.P. A.B. together with J.R. conceptualized the necessary 
simulations and conducted the majority of the computational simulations with the aid of R.L. Finally, J.R, M.A., M.E.-E., R.L., A.B. and K.D.J. all participated in the discussions of reaction mechanism and helped develop this mechanistic study. A.B. and K.D.J. jointly drafted the manuscript.

\section{ACKNOWLEDGMENT}

We would like to thank the Center for High Entropy Alloy Catalysis (CHEAC) funded by the Danish National Research Foundation (DNRF 149) and the Villum Foundation through the Villum Center for the Science of Sustainable Fuels and Chemicals (\#9455) for funding this work. M.E.E. and K.D.J. would like to thank the Independent Research Fund Denmark for the award of a DFF-Research Project 1 grant (9041-00224B). M.E.-E. acknowledges the Villum Foundation for financial support through a Villum Young Investigator Grant (project number: 19142). J.D. and D.Z. would like to thank the funding from the China Scholarship Council (CSC).

\section{ABBREVIATIONS}

$\mathrm{CA}$, chronoamperometry; $\mathrm{CV}$, cyclic voltammogram/voltammetry; $\mathrm{CO}_{2} \mathrm{RR}, \mathrm{CO}_{2}$ reduction reaction; DFAFC, direct formic acid fuel cell; DMFC direct methanol fuel cell; DFT, density functional theory; fcc, face centered cubic; FAOR, formic acid oxidation reaction; FC, fuel cell; GCHE, generalized computational hydrogen electrode; HER, hydrogen evolution reaction; $\mathrm{H}_{\mathrm{UPD}}$, hydrogen underpotential deposition; MNC, metal-nitrogen-carbon; OER, oxygen evolution reaction; ORR, oxygen reduction reaction; RHE, reversible hydrogen electrode; RDE, rotating disk electrode; SI, supporting information;

\section{REFERENCES}

(1) Seh, Z. W.; Kibsgaard, J.; Dickens, C. F.; Chorkendorff, I.; Nørskov, J. K.; Jaramillo, T. F. Combining Theory and Experiment in Electrocatalysis: Insights into Materials Design. 
Science 2017, 355 (6321), eaad4998. https://doi.org/10.1126/science.aad4998.

(2) Peter, S. C. Reduction of $\mathrm{CO} 2$ to Chemicals and Fuels: A Solution to Global Warming and Energy Crisis. ACS Energy Lett. 2018, 3 (7), 1557-1561. https://doi.org/10.1021/acsenergylett.8b00878.

(3) Cherevko, S.; Zeradjanin, A. R.; Topalov, A. A.; Kulyk, N.; Katsounaros, I.; Mayrhofer, K. J. J. Dissolution of Noble Metals during Oxygen Evolution in Acidic Media. ChemCatChem 2014, 6 (8), 2219-2223. https://doi.org/10.1002/cctc.201402194.

(4) Ong, B. C.; Kamarudin, S. K.; Basri, S. Direct Liquid Fuel Cells: A Review. Int. J. Hydrogen Energy $\quad \mathbf{2 0 1 7}, \quad 42 \quad$ (15), 10142-10157. https://doi.org/10.1016/j.ijhydene.2017.01.117.

(5) Yajima, T.; Uchida, H.; Watanabe, M. In-Situ ATR-FTIR Spectroscopic Study of ElectroOxidation of Methanol and Adsorbed CO at Pt-Ru Alloy. J. Phys. Chem. B 2004, 108 (8), 2654-2659. https://doi.org/10.1021/jp037215q.

(6) Mekazni, D. S.; Arán-Ais, R. M.; Ferre-Vilaplana, A.; Herrero, E. Why Methanol ElectroOxidation on Platinum in Water Takes Place Only in the Presence of Adsorbed OH. ACS Catal. 2022, 1965-1970. https://doi.org/10.1021/acscatal.1c05122.

(7) Nitopi, S.; Bertheussen, E.; Scott, S. B.; Liu, X.; Engstfeld, A. K.; Horch, S.; Seger, B.; Stephens, I. E. L.; Chan, K.; Hahn, C.; Nørskov, J. K.; Jaramillo, T. F.; Chorkendorff, I. Progress and Perspectives of Electrochemical CO2 Reduction on Copper in Aqueous Electrolyte. Chem. Rev. 2019, $119 \quad$ (12), 7610-7672. https://doi.org/10.1021/acs.chemrev.8b00705.

(8) Chen, X.; Granda-Marulanda, L. P.; McCrum, I. T.; Koper, M. T. M. How Palladium Inhibits CO Poisoning during Electrocatalytic Formic Acid Oxidation and Carbon Dioxide Reduction. Nat. Commun. 2022, 13 (1), 1-11. https://doi.org/10.1038/s41467-021-277935 .

(9) Hori, Y.; Takahashi, I.; Koga, O.; Hoshi, N. Selective Formation of C2 Compounds from Electrochemical Reduction of CO2 at a Series of Copper Single Crystal Electrodes. J. Phys. Chem. B 2002, 106 (1), 15-17. https://doi.org/10.1021/jp013478d.

(10) Bagger, A.; Ju, W.; Varela, A. S.; Strasser, P.; Rossmeisl, J. Electrochemical CO2 Reduction: Classifying $\mathrm{Cu}$ Facets. ACS Catal. 2019, 9 (9), 7894-7899. https://doi.org/10.1021/acscatal.9b01899.

(11) Sebastián-Pascual, P.; Mezzavilla, S.; Stephens, I. E. L.; Escudero-Escribano, M. StructureSensitivity and Electrolyte Effects in $\mathrm{CO} 2$ Electroreduction: From Model Studies to Applications. ChemCatChem 2019, 11 (16), 3626-3645. https://doi.org/10.1002/cctc.201900552.

(12) Hori, Y.; Wakebe, H.; Tsukamoto, T.; Koga, O. Electrocatalytic Process of CO Selectivity in Electrochemical Reduction of $\mathrm{CO} 2$ at Metal Electrodes in Aqueous Media. Electrochim. Acta 1994, 39 (11-12), 1833-1839. https://doi.org/10.1016/0013-4686(94)85172-7. 
(13) Baldauf, M.; Kolb, D. M. Formic Acid Oxidation on Ultrathin Pd Films on Au(Hkl) and Pt(Hkl) Electrodes. J. Phys. Chem. 1996, 100 (27), 11375-11381. https://doi.org/10.1021/jp952859m.

(14) Oezaslan, M.; Heggen, M.; Strasser, P. Size-Dependent Morphology of Dealloyed Bimetallic Catalysts: Linking the Nano to the Macro Scale. J. Am. Chem. Soc. 2012, 134 (1), 514-524. https://doi.org/10.1021/ja20881621.

(15) Capon, A.; Parsons, R. The Oxidation of Formic Acid at Noble Metal Electrodes Part 4. Platinum + Palladium Alloys. J. Electroanal. Chem. 1975, 65 (1), 285-305. https://doi.org/10.1016/0368-1874(75)85124-0.

(16) Duchesne, P. N.; Li, Z. Y.; Deming, C. P.; Fung, V.; Zhao, X.; Yuan, J.; Regier, T.; Aldalbahi, A.; Almarhoon, Z.; Chen, S.; Jiang, D. en; Zheng, N.; Zhang, P. Golden SingleAtomic-Site Platinum Electrocatalysts. Nat. Mater. 2018, 17 (11), 1033-1039. https://doi.org/10.1038/s41563-018-0167-5.

(17) Feliu, J. M.; Herrero, E. Formic Acid Oxidation. Handb. Fuel Cells 2010. https://doi.org/10.1002/9780470974001.f206048.

(18) Joo, J.; Uchida, T.; Cuesta, A.; Koper, M. T. M. M.; Osawa, M. Importance of Acid-Base Equilibrium in Electrocatalytic Oxidation of Formic Acid on Platinum. J. Am. Chem. Soc. 2013, 135 (27), 9991-9994. https://doi.org/10.1021/ja403578s.

(19) Marković, N. M.; Gasteiger, H. A.; Ross, P. N.; Jiang, X.; Villegas, I.; Weaver, M. J. Electro-Oxidation Mechanisms of Methanol and Formic Acid on Pt-Ru Alloy Surfaces. Electrochim. Acta 1995, 40 (1), 91-98. https://doi.org/10.1016/0013-4686(94)00241-R.

(20) Ferre-Vilaplana, A.; Perales-Rondón, J. V.; Feliu, J. M.; Herrero, E. Understanding the Effect of the Adatoms in the Formic Acid Oxidation Mechanism on Pt(111) Electrodes. ACS Catal. 2015, 5 (2), 645-654. https://doi.org/10.1021/cs501729j.

(21) Perales-Rondón, J. V.; Ferre-Vilaplana, A.; Feliu, J. M.; Herrero, E. Oxidation Mechanism of Formic Acid on the Bismuth Adatom-Modified Pt(111) Surface. J. Am. Chem. Soc. 2014, 136 (38), 13110-13113. https://doi.org/10.1021/ja505943h.

(22) Marković, N. M.; Ross Jr., P. N. Surface Science Studies of Model Fuel Cell Electrocatalysts. Surf. Sci. Rep. 2002, 45 (4), 117-229. https://doi.org/10.1016/S01675729(01)00022-X.

(23) Cuesta, Á.; Escudero-Escribano, M.; Lanova, B.; Baltruschat, H. Cyclic Voltammetry, FTIRS, and DEMS Study of the Electrooxidation of Carbon Monoxide, Formic Acid, and Methanol on Cyanide-Modified Pt(111) Electrodes. Langmuir 2009, 25 (11), 6500-6507. https://doi.org/10.1021/la8041154.

(24) Jiang, K.; Zhang, H. X.; Zou, S.; Cai, W. Bin. Electrocatalysis of Formic Acid on Palladium and Platinum Surfaces: From Fundamental Mechanisms to Fuel Cell Applications. Phys. Chem. Chem. Phys. 2014, 16 (38), 20360-20376. https://doi.org/10.1039/c4cp03151b.

(25) Cuesta, A. At Least Three Contiguous Atoms Are Necessary for CO Formation during 
Methanol Electrooxidation on Platinum. J. Am. Chem. Soc. 2006, 128 (41), 13332-13333. https://doi.org/10.1021/ja0644172.

(26) Zhong, W.; Qi, Y.; Deng, M. The Ensemble Effect of Formic Acid Oxidation on PlatinumGold Electrode Studied by First-Principles Calculations. J. Power Sources 2015, 278, 203 212. https://doi.org/10.1016/j.jpowsour.2014.12.071.

(27) Siahrostami, S.; Verdaguer-Casadevall, A.; Karamad, M.; Deiana, D.; Malacrida, P.; Wickman, B.; Escudero-Escribano, M.; Paoli, E.; Frydendal, R.; Hansen, T. W.; Chorkendorff, I.; Stephens, I. E. L.; Rossmeisl, J. Enabling Direct H2O2 Production through Rational Electrocatalyst Design. Nat. Mater. 2013, 12 (12), 1137-1143. https://doi.org/10.1038/nmat3795.

(28) Verdaguer-Casadevall, A.; Deiana, D.; Karamad, M.; Siahrostami, S.; Malacrida, P.; Hansen, T. W.; Rossmeisl, J.; Chorkendorff, I.; Stephens, I. E. L. Trends in the Electrochemical Synthesis of H2O2: Enhancing Activity and Selectivity by Electrocatalytic Site Engineering. Nano Lett. 2014, 14 (3), 1603-1608. https://doi.org/10.1021/nl500037x.

(29) Sun, S. G.; Clavilier, J.; Bewick, A. The Mechanism of Electrocatalytic Oxidation of Formic Acid on Pt (100) and Pt (111) in Sulphuric Acid Solution: An Emirs Study. J. Electroanal. Chem. 1988, 240 (1-2), 147-159. https://doi.org/10.1016/0022-0728(88)80319-X.

(30) Gao, W.; Keith, J. A.; Anton, J.; Jacob, T. Theoretical Elucidation of the Competitive Electro-Oxidation Mechanisms of Formic Acid on Pt(111). J. Am. Chem. Soc. 2010, 132 (51), 18377-18385. https://doi.org/10.1021/ja1083317.

(31) Rice, C.; Ha, S.; Masel, R. I.; Wieckowski, A. Catalysts for Direct Formic Acid Fuel Cells. J. Power Sources 2003, 115 (2), 229-235. https://doi.org/10.1016/S0378-7753(03)000260 .

(32) Rees, N. V.; Compton, R. G. Sustainable Energy: A Review of Formic Acid Electrochemical Fuel Cells. J. Solid State Electrochem. 2011, 15 (10), 2095-2100. https://doi.org/10.1007/s10008-011-1398-4.

(33) Ferre-Vilaplana, A.; Perales-Rondón, J. V.; Buso-Rogero, C.; Feliu, J. M.; Herrero, E. Formic Acid Oxidation on Platinum Electrodes: A Detailed Mechanism Supported by Experiments and Calculations on Well-Defined Surfaces. J. Mater. Chem. A 2017, 5 (41), 21773-21784. https://doi.org/10.1039/c7ta07116g.

(34) Neurock, M.; Janik, M.; Wieckowski, A. A First Principles Comparison of the Mechanism and Site Requirements for the Electrocatalytic Oxidation of Methanol and Formic Acid over Pt. Faraday Discuss. 2009, 140, 363-378. https://doi.org/10.1039/B804591G.

(35) Capon, A.; Parsons, R. The Oxidation of Formic Acid at Noble Metal Electrodes Part III. Intermediates and Mechanism on Platinum Electrodes. J. Electroanal. Chem. 1973, 45 (2), 205-231. https://doi.org/10.1016/S0022-0728(73)80158-5.

(36) Xia, X. H.; Iwasita, T. Influence of Underpotential Deposited Lead upon the Oxidation of $\mathrm{HCOOH}$ in $\mathrm{HClO} 4$ at Platinum Electrodes. J. Electrochem. Soc. 1993, 140 (9), 2559-2565. 
https://doi.org/10.1149/1.2220862.

(37) Tripković, A.; Popović, K.; Adžić, R. Structural Effects in Electrocatalysis : Oxidation of Formic Acid on Single Crystal Platinum Electrodes and Evidence for Oscillatory Behaviour. J. Chim. Phys. 1991, 88 (January), 1635-1647. https://doi.org/10.1051/jcp/1991881635.

(38) Joo, J.; Uchida, T.; Cuesta, A.; Koper, M. T. M.; Osawa, M. The Effect of PH on the Electrocatalytic Oxidation of Formic Acid/Formate on Platinum: A Mechanistic Study by Surface-Enhanced Infrared Spectroscopy Coupled with Cyclic Voltammetry. Electrochim. Acta 2014, 129, 127-136. https://doi.org/10.1016/j.electacta.2014.02.040.

(39) Gennero de Chialvo, M. R.; Luque, G. C.; Chialvo, A. C. Formic Acid Electrooxidation on Platinum, Resolution of the Kinetic Mechanism in Steady State and Evaluation of the Kinetic Constants. ChemistrySelect 2018, 3 (34), 9768-9772. https://doi.org/10.1002/slct.201801725.

(40) Cuesta, A.; Cabello, G.; Gutiérrez, C.; Osawa, M. Adsorbed Formate: The Key Intermediate in the Oxidation of Formic Acid on Platinum Electrodes. Phys. Chem. Chem. Phys. 2011, 13 (45), 20091-20095. https://doi.org/10.1039/c1cp22498k.

(41) Osawa, M.; Komatsu, K. I.; Samjeské, G.; Uchida, T.; Ikeshoji, T.; Cuesta, A.; Gutiérrez, C. The Role of Bridge-Bonded Adsorbed Formate in the Electrocatalytic Oxidation of Formic Acid on Platinum. Angew. Chemie - Int. Ed. 2011, 50 (5), 1159-1163. https://doi.org/10.1002/anie.201004782.

(42) Samjeské, G.; Osawa, M. Current Oscillations during Formic Acid Oxidation on a Pt Electrode: Insight into the Mechanism by Time-Resolved IR Spectroscopy. Angew. Chemie 2005, 117 (35), 5840-5844. https://doi.org/10.1002/ange.200501009.

(43) Peterson, A. A.; Nørskov, J. K. Activity Descriptors for CO2 Electroreduction to Methane on Transition-Metal Catalysts. J. Phys. Chem. Lett. 2012, 3 (2), 251-258. https://doi.org/10.1021/jz201461p.

(44) Bagger, A.; Ju, W.; Varela, A. S.; Strasser, P.; Rossmeisl, J. Electrochemical CO2 Reduction: A Classification Problem. ChemPhysChem 2017, 18 (22), 3266-3273. https://doi.org/10.1002/cphc.201700736.

(45) Bagger, A.; Ju, W.; Varela, A. S.; Strasser, P.; Rossmeisl, J. Single Site Porphyrine-like Structures Advantages over Metals for Selective Electrochemical CO2 Reduction. Catal. Today 2017, 288, 74-78. https://doi.org/10.1016/j.cattod.2017.02.028.

(46) Gómez, R.; Weaver, M. J. Electrochemical Infrared Studies of Monocrystalline Iridium Surfaces. 3. Adsorbed Nitric Oxide and Carbon Monoxide as Probes of $\operatorname{Ir}(100)$ Interfacial Structure. J. Phys. Chem. B 1998, 102 (19), 3754-3764. https://doi.org/10.1021/jp980098s.

(47) Cuesta, A.; Cabello, G.; Hartl, F. W.; Escudero-Escribano, M.; Vaz-Domínguez, C.; Kibler, L. A.; Osawa, M.; Gutiérrez, C. Electrooxidation of Formic Acid on Gold: An ATRSEIRAS Study of the Role of Adsorbed Formate. Catal. Today 2013, 202 (1), 79-86. 
https://doi.org/10.1016/j.cattod.2012.04.022.

(48) Ortiz, R.; Márquez, O. P.; Márquez, J.; Gutiérrez, C. Spectroelectrochemical Evaluation of Rh Microparticles as Electrocatalyst for Carbon Monoxide and Formic Acid Oxidation. Port. Electrochim. Acta 2006, 24 (1), 105-116. https://doi.org/10.4152/pea.200601105.

TheMaterialProject. Material Projects (Rh Pourbaix diagram) https://materialsproject.org/\#apps/pourbaixdiagram/\%7B\%22chemsys $\% 22 \% 3 \mathrm{~A}[\% 22 \mathrm{Rh} \%$ $22] \% 7 \mathrm{D}$.

(50) Rose, A.; Maniguet, S.; Mathew, R. J.; Slater, C.; Yao, J.; Russell, A. E. Hydride Phase Formation in Carbon Supported Palladium Nanoparticle Electrodes Investigated Using in Situ EXAFS and XRD. Phys. Chem. Chem. Phys. 2003, 5 (15), 3220-3225. https://doi.org/10.1039/b302956e.

(51) Gao, D.; Zhou, H.; Cai, F.; Wang, D.; Hu, Y.; Jiang, B.; Cai, W. Bin; Chen, X.; Si, R.; Yang, F.; Miao, S.; Wang, J.; Wang, G.; Bao, X. Switchable CO2 Electroreduction via Engineering Active Phases of Pd Nanoparticles. Nano Res. 2017, 10 (6), 2181-2191. https://doi.org/10.1007/s12274-017-1514-6.

(52) Tura, J. M.; Regull, P.; Victori, L.; de Castellar, M. D. XPS and IR (ATR) Analysis of Pd Oxide Films Obtained by Electrochemical Methods. Surf. Interface Anal. 1988, 11 (8), 447449. https://doi.org/10.1002/sia.740110807.

(53) Saveleva, V. A.; Papaefthimiou, V.; Daletou, M. K.; Doh, W. H.; Ulhaq-Bouillet, C.; Diebold, M.; Zafeiratos, S.; Savinova, E. R. Operando Near Ambient Pressure XPS (NAPXPS) Study of the Pt Electrochemical Oxidation in $\mathrm{H} 2 \mathrm{O}$ and $\mathrm{H} 2 \mathrm{O} / \mathrm{O} 2$ Ambients. J. Phys. Chem. C 2016, 120 (29), 15930-15940. https://doi.org/10.1021/acs.jpcc.5b12410.

(54) Herrero, E.; Feliu, J. M. Understanding Formic Acid Oxidation Mechanism on Platinum Single Crystal Electrodes. Curr. Opin. Electrochem. 2018, 9, 145-150. https://doi.org/10.1016/j.coelec.2018.03.010.

(55) Al Najjar, T.; Ahmed, N.; El Sawy, E. N. Mechanistic Effects of Blending Formic Acid with Ethanol on Pd Activity towards Formic Acid Oxidation in Acidic Media. RSC Adv. 2021, 11 (37), 22842-22848. https://doi.org/10.1039/d1ra01209f.

(56) Miyake, H.; Okada, T.; Samjeské, G.; Osawa, M. Formic Acid Electrooxidation on Pd in Acidic Solutions Studied by Surface-Enhanced Infrared Absorption Spectroscopy. Phys. Chem. Chem. Phys. 2008, 10 (25), 3662. https://doi.org/10.1039/b805955a.

(57) Clavilier, J. Pulsed Linear Sweep Voltammetry with Pulses of Constant Level in a Potential Scale, a Polarization Demanding Condition in the Study of Platinum Single Crystal Electrodes. J. Electroanal. Chem. 1987, 236 (1-2), 87-94. https://doi.org/10.1016/00220728(87)88020-8.

(58) Pizzutilo, E.; Geiger, S.; Freakley, S. J.; Mingers, A.; Cherevko, S.; Hutchings, G. J.; Mayrhofer, K. J. J. Palladium Electrodissolution from Model Surfaces and Nanoparticles. Electrochim. Acta 2017, 229, 467-477. https://doi.org/10.1016/j.electacta.2017.01.127. 
(59) Cherevko, S.; Kulyk, N.; Mayrhofer, K. J. J. Durability of Platinum-Based Fuel Cell Electrocatalysts: Dissolution of Bulk and Nanoscale Platinum. Nano Energy 2016, 29, 275298. https://doi.org/10.1016/j.nanoen.2016.03.005.

TOC

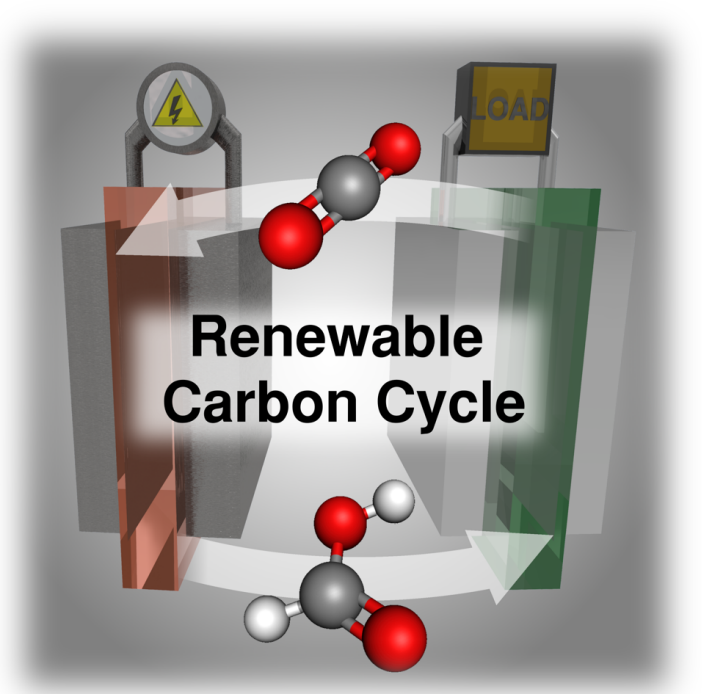

